\title{
Study of Significant Factors Affecting Construction Productivity Using Relative Importance Index in Indian Construction Industry
}

\author{
Saurav Dixit ${ }^{1, *}$, Satya $N$ Mandal $^{1}$, Joseph $V$ Thanikal $^{1}$ and Kinshuk Saurabh ${ }^{2}$ \\ ${ }^{1}$ RICS School of Built Environment, Amity University Noida, 201313, India \\ ${ }^{2}$ Faculty of Finance and Accounting, IIM, Nagpur, India
}

\begin{abstract}
The construction industry of India is the second-largest contributor to the GDP and provides employment to a large population in the country. Its contribution to the GDP is about $8-10 \%$ on an average in the last decade. The objective of this study is to identify and analyze the significant factors affecting construction productivity using relative importance index method with a special focus on the Indian construction industry. A structured questionnaire survey method is used to collect the data from the primary stakeholders of the Indian construction industry including but not limited to consultants, architects, civil contractor, developer, PMC, and academia people. Total of 201 valid responses were received with a response rate of $32 \%$. The value of reliability analysis is above 0.95 , which is considered highly reliable for data-based studies. The findings of the study provide a ranking of factors affecting construction productivity. Most significant factors affecting construction productivity are availability of resources, contractual disputes, scope clarity of the project, design capability, and frequent design changes having the value on relative importance index scale $0.801,0.799,0.790,0.785$, and 0.776 respectively. This research paper concludes that the productivity can be achieved by changing the work culture and reviewing the management process for execution. Which suggests the implementation of best practices and motivation towards achieving the goal of having higher productivity by looking at the factor and analyzing how to promote productivity improvement.
\end{abstract}

\section{Introduction}

The productivity of a country could be measured by the growth rate and the growth in GDP of the country. A country with greater productivity seems to have a great financial structure and growth. The construction industry is one of the main and significant contributors to the economy of a country [1]-[3]. It contributes to the economy about $8-10 \%$ on an average in different countries, and promotes growth, provides employment to the masses, and act as a linkage between the economy and other industries [4]-[9]. The construction industry provides employment to the masses and maintains the flow of materials, machines, funds, and skills from one industry to the other industries. The construction industry works as the backbone of the most developed and developing countries [10]-[14]. As the world population growth increases the demand for new and large scale infra projects, and scope for the new built environment to accommodate the population is also increasing. Which provides the opportunity as well as the challenges to the construction industry [15]-[17]. In the present scenario it encounters a number of issues such as shortage of skilled manpower, delayed in completion of projects on time, loss of productivity, policy-related issues, generation of waste, impact on the environment, pressure to adopt green and sustainable construction, and many other such issues and challenges [9], [15]-[21].

The construction industry of India is the second largest contributor to the GDP and employment in the country. It is contribution about 8-10\% on an average of last one decade. And when we talk about the other world the construction industry is having the same importance in terms of employment generation and contribution to the GDP and growth of the countries. For example the Australian construction industry is the 3rd largest contributor to the GDP of the country $(8-9 \%$ on an average), and provide employment to $9-10 \%$ of the total employment in the country [1], [3], [22]-[24]. Furthermore, it is considered to contribute $12-14 \%$ to employment by 2030 [2], [25]. Construction productivity is defined "as a ratio of a volume measure of output to a volume measure of input use (OECD Manual)" [26,27](Hughes \& Thorpe, 2014)(Hughes \& Thorpe, 2014)[27]. The Australian construction industry is labelled as underperformed while comparing to the other industries of the country such as manufacturing. As per the report of the Australian productivity commission on the performance of the construction industry "the productivity is low and there is a scope to do much better" [28]. A number of researcher-led investigation to the issues and challenges leads to the loss of productivity in the construction industry. The construction project is

\footnotetext{
* Corresponding author: sdixit@ricssbe.edu.in
} 
like a living entity, it has been associated with different set of parameters which ranges from small scale to large scale construction projects, the location of the projects, the motivation of the main stakeholders associated to these projects, the ground conditions of the project, the leadership of the project, and many more such issues [29]. Furthermore, these parameters were not the only constrained to the success of any construction project. There are much more generalized and sophisticated attributes that impacts productivity of construction projects were: poor site management, continuous over time, site welfare, lack of trust, better training, measurement of productivity, availability of material, frequent design changes, scope clarity, logistics and supply chain management, and many other attributes [1], [3], [23]-[25], [30]-[32].

So, country like India also established the National Productivity Council (NPC) in National level organization to productivity culture in 1958 by the Ministry of industry. NPC work with client to accelerate the productivity which Indian helps in increasing portraits, competitiveness, reliability with safety, and gets better quality. NPC helps in making decisions systems and processes work culture and having customer satisfaction with both internal and external through its reliable and huge database. This autonomous Council also helps in monitoring reviewing and making strategies to enhance the productivity. The services by NPS helps in bringing the economic growth and quality of life. Productivity is defined as the major rate at which assign work is performed. Several Agencies / body define the productivity as the ratio of input and output or the output per unit of the total output. In construction industry productivity is measured in weights, volume and length and the cost of labour or Men-hr work. Various company adopts various methods to measure their productivity for the construction cost estimation.

The productivity analysis helps the company to have the estimate and increase the profitability. they make several plans and change in the organization to increase the productivity and implement it. This industry faces and lots of challenges and problems in implementation of productivity growth.

\subsection{Scope of the study}

As an industry the productivity is lowest when it comes to the construction industry because of various challenges and factor affecting the industry growth and economics. So, this research study is done to analyze and identify the various internal and external factors affecting the Construction industry Productivity in India. Firstly, in construction industry various factor affecting the productivity and the working culture of the industries are identified. And furthermore, analysed using statistical tools and techniques

\section{Literature review}

Various studies and research have been carried out to identify the various factors affecting construction labour productivity. "According to the American Association of cost engineers they defined the productivity as a relative measure of labour efficiency either good or bad when compared to an established base or norms." In construction industry it was very difficult to create a benchmark for the productivity calculation and it became very difficult as an absolute to value. So, a various Research and the historical data was collected and made available for the professional Association find the productivity and create a benchmark. Various Research and professionals come up with the list of labour factors from different crops and most of the factors with similar range of impact on labour productivity. Study on the Critical Factors Influencing Labor Productivity in Construction Industry: a total of 30 factors affecting labor productivity were identified. Project manager should focus on the factors to improve the labor productivity and performance, which ultimately leads to higher profit from the construction projects. The result indicates that the most significant factors affecting labor productivity are job related factors and economic and motivational factors. Job related factors which include job security provided by the firm, cultural factors and facilities available at work place. The economic and motivational factor includes providing bonus to the workers, higher wages to motivate the workers, providing performance rewards and conducting motivational plan and activities.

A Critical Literature Review of Labor Productivity in Building Construction "This paper focused on the different research paper where he concluded that there are various factor associated which result into the decreased in the productivity of the craftsman in construction. He concluded various suggestion to overcome the productivity issues. He concluded various construction methods; Low payment; use of technology and the level of mechanization; he also characterized the productivity issues in four group economical, organizational, Physical and socio-physiological; A 1.03 units reduction (or increase) in time overrun causes 1.0 units increase in labor productivity."

Factors Affecting Construction Labor Productivity in Kuwait: "The factors explored were, in addition, classified under the following four primary groups: (1) management; (2) technological; (3) human/labor; and (4) external. , the construction manager should possess a reasonable level of technical skills and contractual knowledge to scrutinize the contract documents and detect potential pitfalls, obscurities, and missing important details and prepare, early enough in the process, a comprehensive list, hence obviate the excessive delays in responding to intermittent and sporadic requests along the course of construction.”

In 2016, Ma et al. concluded that the productivity of the Australian construction industry is low and the main dynamics that could help the productivity problem was technological advancement of the local construction industry. The author recommended that comprehensive study shall be conducted at different levels (activity, project, firm, and the industry level) to analyse the concept of low productivity in the Australian construction industry. In 2017, Gurmu \& Aibinu 
Table 1. The various factors include.

\begin{tabular}{|c|c|}
\hline Attributes & References \\
\hline $\begin{array}{c}\text { increases in land-use regulation } \\
\text { Lack of commitment, Inefficient site management, Poor site coordination, Improper planning and } \\
\text { Lack of clarity in the scope }\end{array}$ & {$[34]$} \\
\hline $\begin{array}{c}\text { Materials shortage, Weather and site conditions, Equipment, breakdown, Drawing deficiencies Lack } \\
\text { of proper tools and equipment's }\end{array}$ & {$[35]$} \\
\hline $\begin{array}{c}\text { Construction workforce, Material availability, Proper tools, Rework, and overcrowded work location } \\
\text { Absenteeism, Rework and lack of material }\end{array}$ & {$[31]$} \\
\hline Lack of material, Inadequate tools, Rework, Instruction delays and Inspection delays & {$[36]$} \\
\hline Planning and scheduling, Equipment's, Working drawings, Materials and Motivation & {$[37],[38]$} \\
\hline $\begin{array}{c}\text { Lack of material, Incomplete drawings, Inspection delays, Incompetent supervisors and Instruction } \\
\text { time }\end{array}$ & $[40]]-[43]$ \\
\hline
\end{tabular}

conducted a study on the impact of safety practices on the productivity of construction projects in Australia. The construction industry is currently experiencing on the boom, and it is having an increase of $3 \%$ in the total construction works as compared to 2017-2018. Several studies were conducted to identify and analyse the factors affecting construction productivity and the Australian construction industry was benefitted from their studies. The author concluded that despite the attempts to increase the productivity of construction projects there was a decline $(-7 \%)$ on the productivity of the construction projects. Thus, there is a need for a comprehensive study to identify and analyse the factors affecting the on-site construction productivity and to propose a model framework to control the factors affecting construction productivity in the Australian construction industry. In 2018, Forsythe studied the construction productivity measurement on building projects. The author highlighted the significant importance of construction productivity and the procedure to measure the productivity of the building project in Australia. The author also highlights the factors affecting construction productivity in Australia. And recommended the "multifactor measurement inclusive of labour and temporary production infrastructure inputs, set against Gross Floor Area outputs". In 2018, provides a comparison between nominal and real construction labour productivity, and concluded that the construction labour productivity in developed countries is relatively higher as compared to the developing countries, but it does not mean that the developed countries were not facing issues of loss of productivity and other issues with productivity enhancement.

Problems Influencing Craftsmen's Productivity in Nigeria: "This paper has demonstrated how productive times often filter away in varying and significant degrees in Nigeria. Unproductive time was found to be $39 \%$ in steel fixing and $40 \%$ in both joinery and bricklaying trades. The main cause of lack of materials was identified as the outright shortage of materials on site, together with other causes such as excessive paper work before requisition or on-site transportation difficulties."
"The principal problems of irregular supply of material and poor plant maintenance often result from non-payment for materials supplied and repairs undertaken. Site agents and supervisors need to programme their projects more thoroughly to anticipate problems". He Further added that the Employee should have their knowledge updated by the continuous professional development and various training. These professional developments can be built by giving training and giving them the crash course about the specific and required competencies required for the project. Various contractors and specialist EPC contractor and company's headset billion-dollar construction and they find that the inefficiency factors impacting the labour reduces the labour productivity so best construction planning practices should be considered and analyze live factor in original, various forms to accelerate and reflect all the conditions that we used to estimate and fund the project. In construction each project is unique bites designs sized capacity utility in location orientation and so on. It becomes very difficult to create a productivity benchmark and standard productivity measures to increase the output. Projects are usually planned and budgeted according to the historical data and the previous experience. It becomes important to consider the differentiator and variables we need for the project and the various factors accordingly. All the projects are unique in themselves and have with various variables impacting the productivity.

So, it becomes important for the industry to establish and build the efficiency table. Various companies have their standards practices survey historical data case studies which help them to develop a table of factor for labour in efficiency and hence help them in Planning the project. "According to the independent project analysis group, and average of over 35\% of all the construction project will have a major change. change in a project of any kind usually means there will be associated productivity impact that can be attributed to inefficiency." Usually EPC companies and contractors have a defined works score duration start date and other parameters based on their contract. Originally the projects have been planned for the construction Partially Impacts and efficiency another impact arise when there 
is a need for new or additional materials or equipment which affects the duration and they scheduled work this may increase the ideal time of workers waiting for the materials such changes also impact the productivity of the project. This ideal time or delay in this schedule because when we increase, and the work area is over crowded with worker causing a productivity drop and hence more time is lost for the project. "According to a study of over 12000 projects conducted by the independent project analysis group on average over 35\% of All Construction project will have a major change":

1) $25 \%$ of project sleep over $20 \%$

2) $25 \%$ of all projects grow in the field by over $30 \%$

These changes are the major changes in project have the direct impact on the project budget and schedule. but also creates the problem with labour inefficiency and this in efficiency in construction is the biggest contributor for project cost overrun. Technology cannot eliminate efficiency but Helps in analyzing and identifying the inefficiency in the planning of the construction. with the use of various technological tools and Technology the work planner can identify labor inefficiency and help to plan and manage their impact on productivity.

\subsection{Classification of productivity and productive time}

The British standards institution defines a working day as "the normal daily or weekly or as agreed in the local train situations or within the industry and beyond which overtime rate may be payable.” The construction working day in India usually starts at 8 a.m. and ends at 8 p.m., With an official break between 12 noon and 1 p.m. Broadly the working time is usually classified into two groups absence time and attendance time. absence time is defined as when the work is absent from the work during the normal working days a week, while the attendance time is defined as the total time spent by work at the work.

\section{Research methodology}

The methodology adopted for the study is to identify the attributes affecting construction productivity form the literature review and expert interviews. A total of 56 attributes have been identified and shortlisted to 40 on the basis of pilot survey analysis. The attributes have been analysed and explained in detail in this paper.

\subsection{Questionnaire Survey}

The draft of questionnaire was prepared from the various literature and then modified according to the research objective to get the responses. This questionnaire was reviewed by are faculties and scholars in the area of construction management. After which A final questionnaire was prepared to be circulated for the responses.

To achieve the desired objective the data for the study were collected through both online and off-line modes i.e. A structured questionnaire survey and direct on-site data collection techniques have been used and a total of 206 valid responses from construction professionals and academicians from all over India. The response rate for this study is about $34 \%$ i.e. a total of 605 professionals have been contacted for the purpose of data collection. To complete this project research, we have adopted the method of 2 approach system. First approach is to develop the questionnaire and circulate it to the respondent and the second approach would be to analyses the data using the relative importance index (RII). after the completion of first approach identify each variables and defect affecting the construction industry labour productivity. Questionnaire was circulated by emails WhatsApp other social media platform to the various professionals associated with the construction industry. this survey was circulated and submitted within two weeks, by the end of 2 weeks we were able to get the responses of around 35 for the pilot project survey.

The questionnaire consists of 40 questions attempting to cover the major attributes affecting on-site productivity. These attributes have been identified with the help of various studies on construction labour productivity. The following tests have been applied on the data collected through structured questionnaire survey:

I. Reliability analysis to check the consistency of data collected.

II. RII (relative importance index) to priorities the attributes based on weighted average of responses received

The data and the responses of various professionals from the contractors for designer's consultants and academicians. Complete the project Research and to save the cause we took the help of question Pro tools to collect the data. Various factors affecting productivity was collected from the literature review from folk's journal articles seminar conferences and websites. these factors affecting productivity was accumulated and redesign for the questionnaire to be asked. To meet the research objectives, the responses was collected from various departments of construction such as contractor's designers PMC.

\section{Analysis and result}

A descriptive statistic of the data, reliability analysis, and relative importance index is calculated from the factors classified in the questionnaire.

According to the RII various factors Affecting the labour productivity Was ranked Accordingly.

\subsection{Relative importance index (RII)}

Reliability analysis is the measure of consistency of data collected for the study, and its value lies from $0-1$. The greater is the value is considered more reliable for the study [44].

Table 2. Reliability Statistics.

\begin{tabular}{|l|l} 
Cronbach's Alpha & N of Items
\end{tabular}




$$
0.965
$$

40

\subsection{Relative importance index (RII)}

Relative importance index is the sum of all the responses divide by the number of responses and the maximum number of likert scale i.e. weighted average of all the responses received. The RII method is one of the most utilized and having a good reliable value while ranking the attributes/factors using structured questionnaire survey [45]-[47].

Most significant factors affecting construction productivity are Availability of resources, Contractual disputes, Scope clarity of the project, Design capability and frequent design changes, and having the value on Rework Relative importance index scale 0.80199, $0.799005, \quad 0.79005, \quad 0.785075$, and 0.776119

Table 3. Relative importance index.

\begin{tabular}{|c|c|c|c|c|}
\hline Sr. No. & Description of attributes & $\begin{array}{l}\text { Total } \\
\text { score }\end{array}$ & $\begin{array}{l}\text { Total number of } \\
\text { responses }\end{array}$ & RII \\
\hline 1 & Availability of resources & 806 & 201 & 0.80199 \\
\hline 2 & Contractual disputes & 803 & 201 & 0.799005 \\
\hline 3 & Scope clarity of the project & 794 & 201 & 0.79005 \\
\hline 4 & Design capability and frequent design changes & 789 & 201 & 0.785075 \\
\hline 5 & Rework & 780 & 201 & 0.776119 \\
\hline 6 & Coordination between all stakeholders & 778 & 201 & 0.774129 \\
\hline 7 & $\begin{array}{l}\text { Project managers authority to take financial decisions and } \\
\text { selecting key team members }\end{array}$ & 776 & 201 & 0.772139 \\
\hline 8 & Timely payment of completed works & 775 & 201 & 0.771144 \\
\hline 9 & Site clearance/availability & 775 & 201 & 0.771144 \\
\hline 10 & Ability to handle the crisis by the pm & 775 & 201 & 0.771144 \\
\hline 11 & Use of inappropriate planning tools and techniques & 767 & 201 & 0.763184 \\
\hline 12 & Quality & 758 & 201 & 0.754229 \\
\hline 13 & Leadership qualities & 756 & 201 & 0.752239 \\
\hline 14 & Top management support to pm & 756 & 201 & 0.752239 \\
\hline 15 & Human resource and labour strike & 753 & 201 & 0.749254 \\
\hline 16 & Cost & 748 & 201 & 0.744279 \\
\hline 17 & Project coordination meetings & 744 & 201 & 0.740299 \\
\hline 18 & Inadequate project formulation in the beginning & 742 & 201 & 0.738308 \\
\hline 19 & $\begin{array}{llll}\begin{array}{l}\text { Obsolete construction } \\
\text { technology }\end{array} & \text { equipment's, methods and } \\
\end{array}$ & 742 & 201 & 0.738308 \\
\hline 20 & Conflict of interest among team members & 741 & 201 & 0.737313 \\
\hline 21 & Customer/client satisfaction & 734 & 201 & 0.730348 \\
\hline 22 & Conflict of interest among team members & 734 & 201 & 0.730348 \\
\hline 23 & $\begin{array}{l}\text { Availability of training and development for enhancing of } \\
\text { skills }\end{array}$ & 731 & 201 & 0.727363 \\
\hline 24 & Selection of pm with proven track record & 728 & 201 & 0.724378 \\
\hline 25 & Supply chain & 704 & 201 & 0.700498 \\
\hline 26 & Willingness to adopt change & 704 & 201 & 0.700498 \\
\hline 27 & Claim genuineness & 698 & 201 & 0.694527 \\
\hline 28 & Regular budget update & 696 & 201 & 0.692537 \\
\hline 29 & Social skills of key team managers & 695 & 201 & 0.691542 \\
\hline 30 & Working hours & 691 & 201 & 0.687562 \\
\hline 31 & $\begin{array}{l}\text { Developing and maintaining a short and informal line of } \\
\text { communication }\end{array}$ & 682 & 201 & 0.678607 \\
\hline 32 & Urgency emphasized by the owner while issuing tender & 677 & 201 & 0.673632 \\
\hline 33 & Ability to delegate authority & 673 & 201 & 0.669652 \\
\hline 34 & political and economic environment & 669 & 201 & 0.665672 \\
\hline 35 & Exceptional difference between client and architect & 669 & 201 & 0.665672 \\
\hline 36 & Interpersonal skills & 666 & 201 & 0.662687 \\
\hline 37 & Climate conditions & 660 & 201 & 0.656716 \\
\hline 38 & Interest and inflation rates & 660 & 201 & 0.656716 \\
\hline 39 & Availability of accurate historical information & 645 & 201 & 0.641791 \\
\hline 40 & Social environment & 597 & 201 & 0.59403 \\
\hline
\end{tabular}


respectively. The respondent thinks that the improper supervision at this site as the main factor to have low productivity preceded by poor sight management. Furthermore, Improper Supervision by the site engineer can decrease the productivity if the supervision is not done correctly and on time. Most of the managerial and the management of the organization is responsible for the loss of productivity during the execution and suggest that the management and the supervision should be done on the basis to increase the productivity. Improper drawing management and poor material planning by the procurement department also impact the productivity. This shows the measure productivity loss is dipped in the supervision to the labour and the site and poor Material Management by the management team of the company. the increase in the planning and the management department can help to increase the productivity of the labour and hence the project would be completed on time within the budget. In India we have Has huge shortage of skilled workforce which means the labour with skills have the major impact in increasing the productivity of the nation/ construction. Construction industry with an experienced labour can do they work faster and effectively which will ultimately increase the productivity. Skills of labour is there another concern for the industry because in India the training program is designed to scale the labour although the skill development programmed, is undergoing by the government of India. in the coming years this will increase a labour skills and which will be helping the industry increasing the Productivity and to discuss with work with effectiveness.

\section{Conclusion and Recomendation}

This research study has identified and analyses the factors associated with the productivity. the results obtained shows that the management team needs to work more on the planning and clarity of the work, it's not are the technical aspects contributing to the decreased productivity, The lack of spending less time on planning by the management is amongst the main factor to contribute the less productivity so an organization need to concentrate and work on it . The improper supervision by the employee contribute to another major factor followed by the poor sight management to affect the productivity [20], [34], [44], [48]-[50]. This study also shows that the motivation of the employee/ labour is also one of the factors which contributes to it. For the productivity can be attained by training a construction managers and creating the right type of leadership on site, industry can also create a leave without pay to increase the productivity and efficiency of the project, moreover the managers should also have a sound technical and managerial skills which will help to manage the contract document and detect the problems which can affect the project delay and cost overrun. The research study shows that the shortage of the experience labor as the major concern among the labour group for decreasing the productivity. to attend this experienced and skilled labour company or an organization can have a special training program, which may help to have skilled labour at this site. This analysis and Research study help to fill the gap of the knowledge and also helps in understanding the important factors affecting the productivity and also it shows as the path to increase the efficiency of employee and the labour.

\section{References}

[1] M. Chalker and M. Loosemore, "Trust and productivity in Australian construction projects: A subcontractor perspective,” Eng. Constr. Archit. Manag., vol. 23, no. 2, pp. 192-210, 2016.

[2] F. C. Chia, M. Skitmore, J. Gray, and A. Bridge, "International comparisons of nominal and real construction labour productivity,” Eng. Constr. Archit. Manag., vol. 25, no. 7, pp. 896-915, 2018.

[3] A. T. Gurmu, "Identifying and prioritizing safety practices affecting construction labour productivity: An empirical study,” Int. J. Product. Perform. Manag., 2019.

[4] D. C. Dacy, "Productivity and price trends in construction since 1947,” Rev. Econ. Stat., vol. 47, no. 4, pp. 406-411, 1965.

[5] S. G. Allen, "Why Construction Industry Productivity Is Declining Author ( s ): Steven G . Allen Source : The Review of Economics and Statistics, Vol . 67 , No . 4 ( Nov ., 1985 ), pp . 661-669 Published by: The MIT Press Stable URL : http://www.jstor.org/stable/1924," vol. 67, no. 4, pp. 661-669, 2016.

[6] E.-B. Lee, H. Lee, and C. W. Ibbs, "Productivity Aspects of Urban Freeway Rehabilitation with Accelerated Construction,” J. Constr. Eng. Manag., vol. 133, no. 10, pp. 798-806, 2007.

[7] U. C. Gatti, G. C. Migliaccio, S. M. Bogus, and S. Schneider, “An exploratory study of the relationship between construction workforce physical strain and task level productivity," Constr. Manag. Econ., vol. 32, no. 6, pp. 548564, 2014.

[8] L. Borg and H.-S. Song, "Quality Change and Implications for Productivity Development: Housing Construction in Sweden 1990-2010,” J. Constr. Eng. Manag., vol. 141, no. 1, p. 05014014, 2015.

[9] I. Mahamid, "Contractors perspective toward factors affecting labor productivity in building construction,” Eng. Constr. Archit. Manag., vol. 20, no. 5, pp. 446-460, 2013.

[10] A. V. Thomas and J. Sudhakumar, "Critical analysis of the key factors affecting construction labour productivity -an Indian perspective,” Int. J. Constr. Manag., vol. 13, no. 4, pp. 103-125, 2013.

[11] H. Karimi, T. R. B. Taylor, and P. M. Goodrum, "Analysis of the impact of craft labour availability on North American construction project productivity and schedule performance,” 
Constr. Manag. Econ., vol. 35, no. 6, pp. 368380, 2017.

[12] L. Ruddock and S. Ruddock, "Evaluation of trends in the UK construction industry using growth and productivity accounts," Constr. Manag. Econ., vol. 29, no. 12, pp. 1229-1239, 2011.

[13] R. Pellegrino, N. Costantino, R. Pietroforte, and S. Sancilio, "Construction of multi-storey concrete structures in Italy: Patterns of productivity and learning curves," Constr. Manag. Econ., vol. 30, no. 2, pp. 103-115, 2012.

[14] B. Vogl, "Measuring Construction: Prices, Output and Productivity," Constr. Manag. Econ., vol. 33, no. 9, pp. 775-777, 2015.

[15] Y. Li and C. Liu, "Malmquist indices of total factor productivity changes in the Australian construction industry," Constr. Manag. Econ., vol. 28, no. 9, pp. 933-945, 2010.

[16] W. Chancellor and W. Lu, “A Regional and Provincial Productivity Analysis of the Chinese Construction Industry: 1995 to 2012,” J. Constr. Eng. Manag., vol. 142, no. 11, p. 05016013, 2016.

[17] D. Zhai, P. M. Goodrum, C. T. Haas, and C. H. Caldas, "Relationship between Automation and Integration of Construction Information Systems and Labor Productivity,” J. Constr. Eng. Manag., vol. 135, no. 8, pp. 746-753, 2009.

[18] E. M. Generalova, V. P. Generalov, and A. A. Kuznetsova, "Modular Buildings in Modern Construction,” Procedia Eng., vol. 153, pp. 167172, 2016.

[19] L. Ma, C. Liu, and A. Mills, “Construction labor productivity convergence: a conditional frontier approach,” Eng. Constr. Archit. Manag., vol. 23, no. 3, pp. 283-301, 2016.

[20] S. Dixit, “Analysing Enabling Factors Affecting the On-site Productivity in Indian Construction Industry,” Period. Polytech. Archit., vol. 49, no. 2, pp. 185-193, Nov. 2018.

[21] P. Minde, "Labour productivity in construction activity,” vol. 5, no. I, p. 2012, 2012.

[22] S. Dabirian, M. Khanzadi, and R. Taheriattar, "Qualitative Modeling of Sustainability Performance in Construction Projects Considering Productivity Approach,” Int. J. Civ. Eng., vol. 15, no. 8, pp. 1143-1158, 2017.

[23] P. Forsythe, "Extending and operationalizing construction productivity measurement on building projects," Constr. Manag. Econ., vol. 36, no. 12, pp. 683-699, 2018.

[24] A. T. Gurmu and A. A. Aibinu, "Construction Equipment Management Practices for Improving Labor Productivity in Multistory Building Construction Projects,” J. Constr. Eng. Manag., vol. 143, no. 10, p. 04017081, 2017.

[25] L. Ma, C. Liu, and A. Mills, "Construction labor productivity convergence: A conditional frontier approach,” Eng. Constr. Archit. Manag., vol. 23, no. 3, pp. 283-301, 2016.

[26] M. Productivity and O. Manual, "Measurement of aggregate and industry-level productivity growth,” Organ. Econ. co-operation Dev., pp. 11-18, 2001.

[27] R. Hughes and D. Thorpe, “A review of enabling factors in construction industry productivity in an Australian environment," Constr. Innov., vol. 14, no. 2, pp. 210-228, 2014.

[28] Australian Productivity Commission, Public infrastructure: inquiry report, vol. 1, no. 71. 2014.

[29] S. Dixit, S. N. Mandal, J. V. Thanikal, and K. Saurabh, "Evolution of studies in construction productivity: A systematic literature review (2006-2017)," Ain Shams Eng. J., no. xxxx, 2019.

[30] M. Chalker and M. Loosemore, “Trust and productivity in Australian construction projects: a subcontractor perspective," Eng. Constr. Archit. Manag., vol. 23, no. 2, pp. 192-210, 2016.

[31] M. A. Azman, C. K. H. Hon, M. Skitmore, B. L. Lee, and B. Xia, "A Meta-frontier method of decomposing long-term construction productivity components and technological gaps at the firm level: evidence from Malaysia,” Constr. Manag. Econ., vol. 37, no. 2, pp. 72-88, 2019.

[32] X. Hu and C. Liu, "Energy productivity and total-factor productivity in the Australian construction industry,” Archit. Sci. Rev., vol. 59, no. 5, pp. 432-444, 2016.

[33] L. Ruddock and S. Ruddock, "Reassessing productivity in the construction sector to reflect hidden innovation and the knowledge economy," Constr. Manag. Econ., vol. 27, no. 9, pp. 871879, 2009.

[34] S. Dixit, S. N. Mandal, J. V Thanikal, and K. Saurabh, "Construction Productivity and Construction Project Performance in Indian Construction Projects,” vol. m, no. July, pp. 379-386, 2018.

[35] R. Kenley, "Productivity improvement in the construction process," Constr. Manag. Econ., vol. 32, no. 6, pp. 489-494, 2014.

[36] L. S. Pheng, G. Shang, and W. K. Foong, "Enhancing Construction Productivity Through Organizational Learning in the Singapore Construction Industry,” Int. J. Constr. Proj. Manag., vol. 8, no. 1, pp. 71-89, 2016.

[37] M. R. Abdul Kadir, W. P. Lee, M. S. Jaafar, S. M. Sapuan, and A. A. A. Ali, "Factors affecting construction labour productivity for Malaysian residential projects," Struct. Surv., vol. 23, no. 1, pp. 42-54, 2005.

[38] S. Dixit, S. N. Mandal, A. Sawhney, and S. Singh, "Relationship between skill development and productivity in construction sector: A literature review,” Int. J. Civ. Eng. Technol., vol. 8, no. 8, 2017.

[39] E. A. Poirier, S. Staub-French, and D. Forgues, "Measuring the impact of BIM on labor productivity in a small specialty contracting 
enterprise through action-research,” Autom.

Constr., vol. 58, pp. 74-84, 2015.

[40] X. Li, G. Q. Shen, P. Wu, H. Fan, H. Wu, and Y. Teng, "RBL-PHP: Simulation of Lean

Construction and Information Technologies for Prefabrication Housing Production,” J. Manag. Eng., vol. 34, no. 2, p. 04017053, 2017.

[41] S. Pheng Low, "Quantifying the relationships between buildability, structural quality and productivity in construction," Struct. Surv., vol. 19, no. 2, pp. 106-112, 2001.

[42] S. Durdyev and J. Mbachu, "On-site labour productivity of New Zealand construction industry: Key constraints and improvement measures,” Australas. J. Constr. Econ. Build., vol. 11, no. 3, pp. 18-33, 2011.

[43] R. Fulford and C. Standing, "Construction industry productivity and the potential for collaborative practice,” Int. J. Proj. Manag., vol. 32, no. 2, pp. 315-326, 2014.

[44] S. Dixit and K. Sharma, "Factors Influencing Construction Time Delay on High Rise Projects In India,” in Creative Construction Conference 2019, 2019, pp. 341-346.

[45] S. Dixit and K. Sharma, "Approaches to improve the quality of workplace Built Environment," 2019.

[46] S. Singh, S. Dixit, K. Kumar, and K. Sharma, "ScienceDirect An Introduction to Lean Construction / Visual Management tool in Construction Projects,” vol. 00, no. May, pp. 110, 2019.

[47] S. Dixit and K. Sharma, "A Review of Studies in Structural Health Monitoring ( SHM ),” 2019, pp. 95-99.

[48] S. Dixit, "ScienceDirect Analyzing the Impact of Construction Productivity over Infra Projects : Indian Scenario,” vol. 00, no. May, 2019.

[49] M. N. Shah, S. Dixit, R. Kumar, R. Jain, and K. Anand, "Causes of delays in slum reconstruction projects in India,” Int. J. Constr. Manag., pp. 116, Jan. 2019.

[50] S. Dixit and K. Saurabh, "Impact of Construction Productivity Attributes Over Construction Project Performance in Indian Construction Projects," Period. Polytech. Archit., Apr. 2019. 